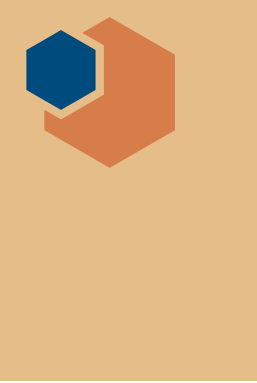

\section{DOE launches the Critical Materials Institute, a new Energy Innovation Hub}

\author{
http://energy.gov/hubs
}

T The growth of the clean energy industry in the United States (US) has stimulated concern about the availability of critical materials for energy. These materials include several rare-earth elements and are key components in many clean energy technologies such as wind turbines, electric vehicles, energy-efficient lighting, and solar panels. While the US is estimated to have nearly $12 \%$ of the world's rare-earth reserves, China has dominated global rare-earth production and supply for more than two decades, peaking at nearly $98 \%$ of global supply in 2010 and providing over $85 \%$ in 2012. In addition to the rare-earth elements, indium and tellurium (used in thin-film solar cells) and lithium (used in batteries) are also critical materials for clean energy technologies.

The health of the clean energy economy in the US hinges both on diversifying supply for these important materials (which will include developing a domestic supply chain) and on finding innovative ways to reduce the need for them. The importance of finding new solutions to address shortages in critical materials has been widely accepted in the materials community and the US government since 2010 when China had temporarily cut off rare-earth supplies to Japan. Since then, China has also imposed restrictions on the amount of rare earths it exports, and Congressional lawmakers have been grappling with the best way to address domestic critical materials shortages. Although several rare-earth and critical materials bills have been introduced in the last two Congresses, none have gained the necessary support to become law.

The US Administration has also recognized the dangers of critical materials shortages and has instituted a number of initiatives to improve domestic materials capabilities. In 2011, President Obama launched the Materials Genome Initiative, a multi-agency effort to speed the discovery of new materials and decrease the cost of their deployment to the market. Further efforts have been made through the Department of Energy (DOE), which has supported research on a range of advanced materials and clean energy technologies. In January 2013, the DOE announced its latest Energy Innovation Hub, the Critical Materials Institute (CMI), which has been awarded $\$ 120$ million to fund research for the next five years.

Alexander King, director of Ames Laboratory, has been named director of the new Hub. The CMI brings together researchers from academia and four DOE national laboratories to col-
Photo courtesy of The Ames Laboratory, USDOE. laborate with industry leaders and find solutions to the critical materials issues the US now faces. The focus of the CMI is multidirectional-researchers plan to address domestic supply-chain issues as well as improve critical materials recycling and develop new substitute materials with more abundant, economically feasible supplies.

Ames Laboratory played a key role in convening the CMI team. CMI partners include Idaho, Lawrence Livermore and Oak Ridge National Laboratories; Brown University; Colorado School of Mines; Iowa State University; Purdue University; Rutgers University; University of California-Davis; Florida Industrial and Phosphate Research Institute, and industry partners Advanced Recovery; Cytec, Inc.; General Electric; Molycorp, Inc.; OLI Systems, Inc.; Simbol Materials; and SpinTek Filtration, Inc. According to King, "the Hub has to actually solve problems, and do so quickly and effectively. That was the philosophy that went into building this team."

The research carried out by the CMI partners will be driven by life cycle, economic, and policy analysis. This approach is best illustrated by looking at relevant materials examples like neodymium versus terbium and europium.

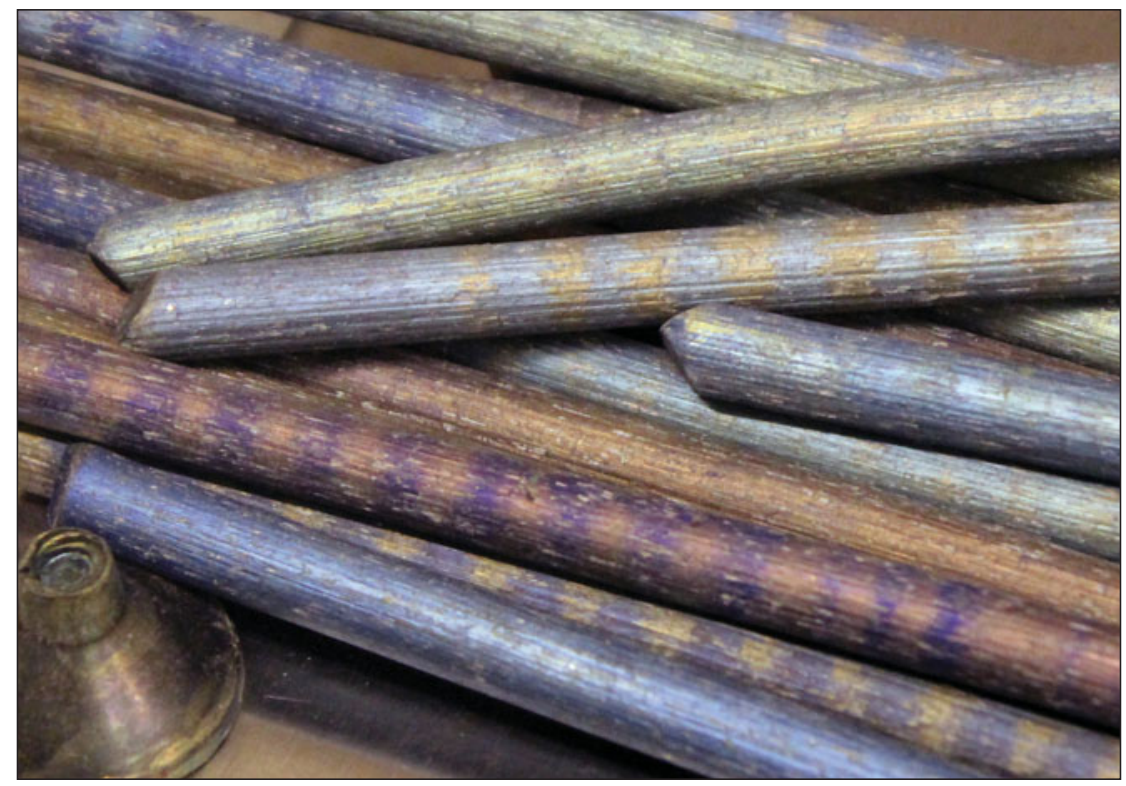


Neodymium is used in magnets - from the very small like those in ear bud speakers to the very large like those in wind turbines and electric vehicle motors. These latter two clean energy technologies use huge amounts of neodymium, vastly increasing demand for the resource. Policy decisions will have a significant impact on the deployment of these technologies, and therefore on the demand for the resource. In this case, the viable solution to address increased neodymium demand is to diversify and increase supply_-perhaps by enabling the US to exploit its own natural resources to produce these elements.

On the other hand, terbium and europium are used in very small amounts in computer screens and fluorescent lights to adjust color. While the current trend for increased efficiency in lighting is driving a transition from incandescent bulbs to fluorescent lights, it is likely that fluorescent lights will eventually also be replaced by more efficient technologies like light-emitting diodes. This means that there will be a small increase in demand for terbium and europium that will eventually wane. The increased demand for these two rare-earth elements can be met largely by recycling and reuse while also developing substitute technologies in parallel.

As technologies and materials supplies develop, the very definition of what is critical is constantly changing. According to Rod Eggert, director of the Colorado School of Mines Division of Economics and Business and deputy director of the CMI, "what is unusual about the CMI is the close coupling of economic analysis with science and engineering research. The economic analysis will directly inform annual decisions about which research projects to continue, which to stop, and which new research areas should be pursued."

While the important task of finding new solutions to address shortages in energy critical materials will continue to be a challenge for researchers and policymakers alike, the establishment of the CMI is an important step in securing the future of the US clean energy economy.

Jennifer A. Nekuda Malik
EU-US joint consultative group meets on science and technology cooperation

$\mathbf{E}$ uropean Union and US officials met in Washington, DC, on February 12 to discuss ways to enhance science, technology, and innovation cooperation. Both sides are committed to the critical role science, technology, and innovation can play in developing the knowledge and technologies that can foster economic growth, create jobs, and help solve shared challenges, such as in health, climate change, and food security.

Groups led by the Director-General for Research and Innovation of the European Commission, Robert-Jan Smits, and Kerri-Ann Jones, US Assistant Secretary of State for Oceans and International Environmental and Scientific Affairs, explored how to advance cooperation in various areas, including materials science. In this field, the two sides discussed already successful work between the European Union, the United States, and Japan in the area of critical raw materials research, and agreed to explore possibilities for collaboration opened up by new US initiatives on advanced materials, particularly in the field of computational modeling.

\section{Tax credits available for US clean energy manufacturers} www.energy.gov

$\mathbf{T}$ The US Departments of Energy and the Treasury announced in February the availability of $\$ 150$ million in Advanced Energy Manufacturing Tax Credits for clean energy and energy efficiency manufacturing projects across the United States.

The Advanced Energy Manufacturing Tax Credit was established by the American Recovery and Reinvestment Act-an economic stimulus package passed in 2009 - to support investment in domestic, clean energy, and energy efficiency manufacturing facilities through a competitively awarded 30\% investment tax credit. The initial round provided $\$ 2.3$ billion in credits to 183 projects across the country. The $\$ 150$ million in tax credits are being made available because they were not used by the previous award recipients.

The program supports manufacturing of a range of clean energy products, from renewable energy equipment to energy efficiency products to advanced energy storage and carbon capture technology. These remaining tax credits will be allocated on a competitive basis. Projects will be assessed by the Department of Energy based on the following criteria: commercial viability, domestic job creation, technological innovation, speed to project completion, and potential for reducing air pollution and greenhouse gas emissions. 